\title{
Effect of Formulated Fertilization on Fruit Quality of Early Ripe Peach
}

\author{
Changbing Pu, Qiao Xiao, Jin Wang, Dong Liang and Xiulan Lv* \\ Institute of Pomology and Olericulture, Sichuan Agricultural University, Chengdu, Sichuan, 611130, China
}

\begin{abstract}
Using the early maturing peach variety 'Japan Matsusen' as the test material, nine groups of formula fertilization schemes were set up by orthogonal experiment to study the effects of different fertilization treatments on the quality of peach fruit, in order to obtain the best fertilization formula to improve fruit quality. The results showed that the quality of peach fruit was significantly improved by adding organic fertilizer to the base fertilizer instead of chemical fertilizer. Therefore, by adding organic fertilizer as the base fertilizer, reducing the application amount of chemical fertilizer, and adding other trace element fertilizers can effectively improve the quality of peach fruit.
\end{abstract}

\section{Introduction}

Peach (Amygdalus persica), Rosaceae, native to China's Shaanxi, Gansu, Tibet Plateau, southern Henan, the Yellow River and the Yangtze River watershed, Yunnan and other places. Peach is one of the most temperate fruit trees in the world. It has a long history of cultivation. It was recognized, utilized and domesticated by humans as early as 4,000 years ago. Now it has been cultivated in more than 70 countries and regions, in various provinces of China. The area has cultivation. According to the US Department of Agriculture (USDA) official website data, the total peach production in the world in 2017 was 21.99 million tons, an increase of about $6 \%$ compared with 2016. China, the US and the EU. It is the world's major peachproducing countries and regions, with a total output of 19.173 million tons, accounting for $90.5 \%$ of the world's total output. Among them, China's peach cultivation area and output rank first in the world [1].

Scholars at home and abroad have conducted research on formula fertilization on crops such as Korla pear, tomato, grape, sweet cherry and peach [2-3]. The results of Li Jingqia et al [4] showed that formula fertilization increased the content of Vc and reducing sugar in Korla pear fruit and improved fruit quality. The results of $\mathrm{G}$. Brunetti et al [5] showed that the combination of organic fertilizer and inorganic fertilizer can increase the yield of tomato. Pan Feng et al. carried out research on soil testing and formula fertilization on grape and sweet cherry [6]. The results showed that formula fertilization increased the content of various nutrients in fruits. Zhang Liang ying [7] and other research results on 'Peiqitao', 'Feichengtao' and 'Yanfeng No.1' peach showed that formula fertilization can improve soluble solids and soluble in fruits. The content of sugar and Vc increases the quality of the fruit. Therefore, this experiment uses the early-maturing peach variety 'Japan Matsusaka' in Longquanyi District as the test material, based on soil testing and field experiment, to explore the effects of different fertilizer combinations on the quality of peach fruit, in order to promote and popularize soil testing and fertilization. The peach formula fertilization system provides a reference basis.

\section{Materials and Methods}

\subsection{Material}

The test variety is the 5-year-old 'Japan Matsusaka' (approximately 2,000 kg per mu) growing in Dafo Village, Shanquan Town, Longquanyi District, Chengdu City, Sichuan Province, with an altitude of $524 \mathrm{~m}$ and a planting density of 750 plants $/ \mathrm{hm}^{2}$.

The basic physical and chemical properties of the soil in the preliminary investigation were: organic matter content $14.53 \mathrm{~g} \cdot \mathrm{kg}^{-1}, \mathrm{pH} 6.46$, alkali nitrogen content 76.7 $\mathrm{mg} \cdot \mathrm{kg}^{-1}$, available phosphorus content $9.6 \mathrm{mg} \cdot \mathrm{kg}^{-1}$, and available potassium content $97.5 \mathrm{mg} \cdot \mathrm{kg}^{-1}$, water-soluble calcium content $598.25 \mathrm{mg} \cdot \mathrm{kg}^{-1}$, exchangeable magnesium content $140.23 \mathrm{mg} \cdot \mathrm{kg}^{-1}$, effective iron content $29.32 \mathrm{mg} \cdot \mathrm{kg}^{-1}$, effective manganese content $20.34 \mathrm{mg} \cdot \mathrm{kg}^{-}$ 1 .

The experiment started in the winter, according to the results of soil nutrient content determination, the target yield method was used to determine the amount of fertilizer application, and the soil fertility formula balanced fertilization program was formulated. Calculated with a yield of $30,000 \mathrm{~kg} \cdot \mathrm{hm}^{-2}$, germination fertilizer 0.25 $\mathrm{kg}$ urea $+0.15 \mathrm{~kg}$ borax was applied 2 weeks before germination, and monoammonium phosphate in the strong fruit fertilizer was applied $0.5,0.8,1.1 \mathrm{~kg}$ per plant, and potassium sulfate was applied at 1.15 per plant. The three levels of 1.15 and $1.75 \mathrm{~kg}$ were applied during the fruit expansion period. The base fertilizer was applied with

*Corresponding author's e-mail: xllvjj@163.com 
$15 \mathrm{~kg}$ of organic fertilizer per plant,and combined with $2 \mathrm{~kg}$ of superphosphate $+0.35 \mathrm{~kg}$ of urea + potassium sulfate $1.5 \mathrm{~kg}+0.06 \mathrm{~kg}$ of magnesium sulfate. $10-15$ days of application, using orthogonal test design, a total of 9 treatments, with a single plant as a community, repeated 3 times, a total of 30 . The local conventional fertilization was used as the control: budding fertilizer $2.5 \mathrm{~kg}$ compound fertilizer $+0.5 \mathrm{~kg}$ urea per plant, strong fruit fertilizer $2 \mathrm{~kg}$ compound fertilizer per plant, base fertilizer $5 \mathrm{~kg}$ dry chicken manure + compound fertilizer $3 \mathrm{~kg}+$ urea $0.5 \mathrm{~kg}$. After the peach fruit matures, the fruit is harvested in four directions of the east, south, west and north of the test plant. Five fruits are collected from each tree as samples. After being labeled, they are placed in an ice box and brought back to the laboratory for fruit quality determination.

\subsection{Methods}

The fruit firmness was measured by GY-3 fruit hardness tester, and the longitudinal and transverse diameters of the fruit were measured by cursor calipers and the fruit shape index was calculated. The fruit shape index $=$ vertical diameter/transverse diameter; the solubility was measured by a handheld TD-45 portable sugar meter. The content of solids was determined by fluorenone colorimetric method;the titratable acid content was determined by $\mathrm{NaOH}$ titration; the $\mathrm{Vc}$ content was determined by molybdenum blue colorimetric method [8].

\section{Results and Discussion}

\subsection{Effect of Formulated Fertilization on Fruit Quality of 'Japan Matsusaka' Peach}

It can be seen from the table that the fruit quality can be improved on a certain basis by increasing the application amount of organic fertilizer on the original basis and assisting the rational fertilizer application scheme. In terms of fruit appearance quality, the single fruit weight of 'Japan Matsusaka' had different degrees of improvement after treatment, and the weight of single fruit treated with $3,6,7,8$, and 9 was significantly higher than that of the control, and the other groups were not significantly different; fruit hardness The control group was the highest, followed by treatment 3, which was $3.43 \mathrm{~kg} / \mathrm{cm}^{2}$. The two treatments were significantly higher than the other treatments, and the difference between the other treatments was not significant; the difference between the fruit shape index of the fruit was not significant.

Table 1. Effect of Different Treatments on Fruit Quality of 'Japan Matsusaka'.

\begin{tabular}{ccccccccc}
\hline Treatments & $\begin{array}{c}\text { Single } \\
\text { fruit } \\
\text { weight }\end{array}$ & $\begin{array}{c}\text { Fruit shape } \\
\text { index }\end{array}$ & $\begin{array}{c}\text { TTS } \\
(\%)\end{array}$ & $\begin{array}{c}\text { Hardness } \\
\left(\mathrm{kg} \mathrm{cm}^{-2}\right)\end{array}$ & $\begin{array}{c}\text { Total sugar } \\
(\%)\end{array}$ & $\begin{array}{c}\text { Acid } \\
\text { value } \\
(\%)\end{array}$ & $\begin{array}{c}\text { Vc } \\
\left(\mathrm{mg} \cdot \mathrm{kg}^{-1}\right)\end{array}$ & $\begin{array}{c}\text { Solid acid } \\
\text { ratio }\end{array}$ \\
\hline 1 & $168.63 \mathrm{~d}$ & $0.882 \mathrm{a}$ & $12.67 \mathrm{c}$ & $2.85 \mathrm{~b}$ & $8.14 \mathrm{c}$ & $0.46 \mathrm{a}$ & $18.50 \mathrm{a}$ & $27.54 \mathrm{c}$ \\
2 & $159.92 \mathrm{~d}$ & $0.841 \mathrm{a}$ & $12.23 \mathrm{c}$ & $2.63 \mathrm{~b}$ & $8.22 \mathrm{c}$ & $0.45 \mathrm{a}$ & $18.36 \mathrm{a}$ & $27.18 \mathrm{c}$ \\
3 & $195.14 \mathrm{a}$ & $0.858 \mathrm{a}$ & $12.13 \mathrm{c}$ & $3.43 \mathrm{a}$ & $8.12 \mathrm{c}$ & $0.42 \mathrm{a}$ & $18.59 \mathrm{a}$ & $28.88 \mathrm{c}$ \\
4 & $168.29 \mathrm{~d}$ & $0.831 \mathrm{a}$ & $12.28 \mathrm{c}$ & $2.81 \mathrm{~b}$ & $8.16 \mathrm{c}$ & $0.46 \mathrm{a}$ & $18.27 \mathrm{a}$ & $26.70 \mathrm{c}$ \\
5 & $165.43 \mathrm{~d}$ & $0.854 \mathrm{a}$ & $13.57 \mathrm{~b}$ & $2.98 \mathrm{~b}$ & $9.14 \mathrm{~b}$ & $0.38 \mathrm{~b}$ & $18.87 \mathrm{a}$ & $35.71 \mathrm{~b}$ \\
6 & $173.17 \mathrm{c}$ & $0.851 \mathrm{a}$ & $13.67 \mathrm{~b}$ & $2.80 \mathrm{~b}$ & $9.23 \mathrm{~b}$ & $0.37 \mathrm{~b}$ & $18.12 \mathrm{a}$ & $36.95 \mathrm{~b}$ \\
7 & $174.27 \mathrm{c}$ & $0.852 \mathrm{a}$ & $12.17 \mathrm{c}$ & $2.91 \mathrm{~b}$ & $8.38 \mathrm{c}$ & $0.43 \mathrm{a}$ & $18.12 \mathrm{a}$ & $28.30 \mathrm{c}$ \\
8 & $183.21 \mathrm{~b}$ & $0.849 \mathrm{a}$ & $14.27 \mathrm{a}$ & $3.01 \mathrm{~b}$ & $10.17 \mathrm{a}$ & $0.32 \mathrm{c}$ & $18.44 \mathrm{a}$ & $44.59 \mathrm{a}$ \\
9 & $182.62 \mathrm{~b}$ & $0.851 \mathrm{a}$ & $14.17 \mathrm{a}$ & $3.03 \mathrm{~b}$ & $10.32 \mathrm{a}$ & $0.31 \mathrm{c}$ & $18.25 \mathrm{a}$ & $45.71 \mathrm{a}$ \\
CK & $160.11 \mathrm{~d}$ & $0.862 \mathrm{a}$ & $11.73 \mathrm{~d}$ & $3.72 \mathrm{a}$ & $7.73 \mathrm{~d}$ & $0.42 \mathrm{a}$ & $18.18 \mathrm{a}$ & $26.93 \mathrm{~d}$ \\
\hline
\end{tabular}

Note: The lowercase letters in the table indicate the difference in the same column data at the 0.05 level, the same below.

In terms of fruit inclusions, the content of soluble solids in peach fruit treated with formula fertilization was significantly higher than that in the control. The soluble solids content of treatment 8 and treatment 9 was the highest, reaching $14.27 \%$ and $14.17 \%$, respectively, which was significantly higher than other treatments and controls. The lowest soluble solids content was $12.13 \%$; the total sugar content of the fruit was higher than the control, the highest was 9 for treatment, $10.32 \%$, and the second was treatment for $10.17 \%$, which was significantly higher than other treatments and control groups; The total acid content was significantly lower than that of the control group. Treatments 5, 6, 8, and 9 were significantly lower than other treatments and controls. The total acid content of treatment 9 and treatment 8 was the lowest, $0.31 \%$ and $0.32 \%$, respectively. The total sugar content was significantly higher than the control, in which the content of treatment 9 was the highest at $10.32 \%$; the ratio of solid acid in treatment 8 was $45.71 \%$, which was significantly higher than other treatments and control groups; the effect of formula fertilization on Vc content of fruits was not significant. There was no significant difference in the Vc content between the fruits of the treatment and the control group.

\section{Conclusions}

According to the characteristics of peach growth and fertilizer, the scientific soil testing and formula fertilization should be carried out according to local conditions, and the current application of nitrogen fertilizer and organic fertilizer should be changed. 
Fertilization by soil testing formula, adding $750 \mathrm{~kg}$ of organic fertilizer per mu, reducing fertilizer application by $79.6 \mathrm{~kg}$, reducing the application rate of fertilizer by $30.52 \%$, but the quality of peach fruit is significantly improved, indicating that the application amount of fertilizer can be increased by adding organic fertilizer. The effect of reducing fertilizer and increasing efficiency.

\section{Acknowledgements}

This work was financially supported by the National Key Research and Development Plan of China (2018YFD020 1400).

\section{References}

1. Wang, Z H, Zhuang, E J. (2001) China Fruit Tree: Tao Juan. Beijing: China Forestry Publishing House.

2. WANG, H W, ZHANG, L Z, LU, K G. (2009) Effects of Organic Fertilizer on the Growth and Quality of Red Fuji Apple. J. Anhui Agricultural Sciences, 37: 13572-13573.

3. Pan F, Huang, S P, Lu, X L. (2018) Effects of Formulated Fertilization on Fruit Quality and Soil Physical and Chemical Properties of Abalone Red Plum in Aba Prefecture. J. Shanxi Agricultural Sciences, 64: 8-12.

4. Li, J Q, Mu, Y L, Baier. (2016) Effects of Fertilization on Fruit Quality and Mineral Nutrition Content of Korla Fragrant Pear. J. Xinjiang Agricultural Sciences, 53: 232-239.

5. G· Brunetti, A· Traversa, F- De Mastro. (2019) Short term effects of synergistic inorganic and organic fertilization on soil properties and yield and quality of plum tomato. J. Scientia Horticulture, 252: 342-347.

6. Pan F, Huang, S P, Li, K J. (2018) Effects of Formulated Fertilization on Grape Quality and Soil Physicochemical Properties. J. Hunan Agricultural Sciences, 4: 52-55.

7. ZHANG, L Y, WANG, Y X, WANG, X W. (2008) Effects of Peat on Soil Physical and Chemical Properties and Peach Tree Biological Effects in Tao yuan.J. Journal of Northwest A\&F University, 36: 145-149.

8. Zheng, D Y, An, X N. (2005) Determination of DPPH Free Radical by Bamboo Leaf Extract. J. Journal of Fujian Agriculture and Forestry University, 34: 59-62. 